\title{
Florística del bosque mesófilo de montaña de Molocotlán, Molango-Xochicoatlán, Hidalgo, México
}

\author{
Rafael Mayorga Saucedo, Isolda luna Vega y Othón Alcántara Ayala \\ Herbario FCME, Departamento de Biología, Facultad de Ciencias, Universidad Nacional Autónoma de México, \\ Ciudad Universitaria, Apartado Postal 70-399, México 04510, D.F., México. e-mail: ilv@hp.fciencias.unam.mx
}

\begin{abstract}
Resumen. El bosque mesófilo de Molocotlán abarca parte de dos municipios del estado de Hidalgo, Molango y Xochicoatlán, ambos enclavados dentro de la Sierra Madre Oriental, en la Huasteca Hidalguense. El bosque presenta tres estratos arbóreos, uno alto $(20-30 \mathrm{~m})$, uno medio $(8-20 \mathrm{~m})$ y uno bajo $(2-8 \mathrm{~m})$. Se presenta una lista florística de plantas vasculares constituida por 391 especies, 270 géneros y 112 familias. Los géneros se agruparon de acuerdo con su distribución actual en seis categorías; un alto porcentaje de ellos son exclusivamente americanos.

Palabras clave: Bosque mesófilo de montaña, florística, flora mesoamericana, Hidalgo.

Abstract. The cloud forest of Molocotlán includes part of two municipalities of the Hidalgo State, Molango and Xochicoatlán, and is located in the Huasteca region in the Sierra Madre Oriental. Arboreal vegetation is divided in three vertical strata: high $(20-30 \mathrm{~m})$, medium $(8-20 \mathrm{~m})$, and lower $(2-8 \mathrm{~m})$. The flora of the area includes 391 species, 270 genera, and 112 families. Genera are grouped according to their present distribution in six categories; a high percentaje of them are exclusively American.
\end{abstract}

Key words: Cloud Forest, floristics, Mesoamerican flora, Hidalgo.

$\mathrm{E}$ 1 bosque mesófilo de montaña sensu Rzedowski (1978) es un tipo de vegetación relictual que ocupa menos del $1 \%$ del territorio nacional; según Ortega y Castillo (1996), esta comunidad en el año 1971 ocupaba un área de $17161 \mathrm{~km}^{2}$, o sea $0.86 \%$; para 1991 sólo se registraron $1424 \mathrm{~km}^{2}$ que representan $0.07 \%$ del territorio mexicano.

Su origen complejo y composición híbrida, su distribución archipelágica, la presencia de taxones paleondémicos y neoendémicos y su alta biodiversidad hacen de este tipo de vegetación único y de gran importancia biogeográfica y biológica; lo anterior puede constatarse cuando se observa que esta comunidad contribuye con cerca del $10 \%$ a la flora total del país. Rzedowski (1996) considera que alberga al menos 2500 especies de plantas vasculares, por lo que puede considerarse uno de los tipos de vegetación más diversos por unidad de superficie del territorio mexicano (Rzedowski, 1991; Challenger, 1998).

La gran riqueza y diversidad biológica que presenta el bosque mesófilo de montaña y en general la biota mexicana se ha explicado con base en: 1] su situa- ción geográfica; 2] el variado origen y evolución de sus componentes (Luna et al., 1989), que puede discutirse con base en la hipótesis dispersionista, según la cual México es receptor de elementos de diferentes fuentes, sobre todo si se considera que se ubica en la zona de transición entre las región Neártica y Neotropical, que junto con los elementos endémicos forman un complejo mosaico de especies de diferentes orígenes; 3] su compleja ecología y 4] la historia geológica del país, que puede explicarse bajo dos hipótesis, la de los refugios pleistocénicos, que indica que se basa en los cambios paleoclimáticos del pasado reciente, y la hipótesis de la vicarianza, que propone que hay una estrecha correspondencia entre la historia de la Tierra y la historia geológica, por lo que el número de especies y su distribución endémica tendría que ver con la compleja historia geológica de México (Luna y Espinosa, 1993).

Este tipo de vegetación se presenta bajo ciertas condiciones fisiográficas en regiones de relieve accidentado y en laderas de pendiente pronunciada, principalmente en cañadas protegidas del viento y de 
la insolación. A lo largo de la vertiente del Golfo esta comunidad se distribuye a modo de una faja angosta de islas que va desde el suroeste de Tamaulipas incluyendo porciones de San Luis Potosí, Hidalgo, Puebla y Veracruz hasta el norte de Oaxaca, interrumpiéndose en el Istmo de Tehuantepec y continuándose en Chiapas, tanto en la vertiente septentrional del Macizo Central como a ambos lados de la Sierra Madre en Chiapas. En lo que corresponde a la vertiente Pacífica, la distribución de este tipo de vegetación se presenta aun más dispersa, pero en la Sierra Madre Sur de Guerrero y de Oaxaca sus áreas de distribución están menos fragmentadas (Rzedowski, 1978; 1991).

Miranda y Sharp (1950) señalan que esta comunidad se sitúa entre 1100 y $2000 \mathrm{~m}$ de altitud; por otro lado Rzedowski (1978) señala su límite altitudinal inferior alrededor de los $600 \mathrm{~m}$ y su límite altitudinal superior alrededor de los $2700 \mathrm{~m}$. Estos límites no son totalmente determinantes, sino que se ven seriamente influidos por un ambiente de tipo más húmedo que aquel que presentan los típicos bosques de Quercus y de Pinus, y más cálidos que los propios del bosque de Abies, pero más frescos que aquellos existentes en los bosques tropicales (Ortega y Castillo,
1996). Luna et al. (1994) consideran que este bosque llega a encontrarse alternado con bosques de encino y coníferas, fundamentalmente en cañadas húmedas entre los 2400 a los $3200 \mathrm{~m}$, a menudo contiguos a arroyos y a la vegetación riparia.

Fundamentalmente es un bosque denso con un estrato arbóreo de 15 a $30 \mathrm{~m}$ de altura. Entre los elementos arbóreos más conspicuos se presentan Liquidambar, Clethra, Cleyera, Cornus, Alnus, Quercus, Ostrya, Fagus, Podocarpus, Weinmannia, Magnolia, Oreopanax, Dendropanax y Pinus, entre otros (Rzedowski, 1978). Este estrato arbóreo puede estar agrupado en tres o más subestratos, además de presentarse uno o dos estratos arbustivos y un estrato herbáceo que suele ser pobre cuando la comunidad no está muy perturbada. Las epífitas se encuentran muy bien representadas con las familias Piperaceae, Bromeliaceae y Orchidaceae principalmente. Las pteridofitas encuentran en este tipo de vegetación su mayor abundancia y diversidad, con especies de la familias Polypodiaceae y Cyatheaceae principalmente. La presencia o ausencia de ciertas especies varía de un lugar a otro básicamente por el factor altitudinal, más que por su ubicación latitudinal y longitudinal (Luna et al., 1989).

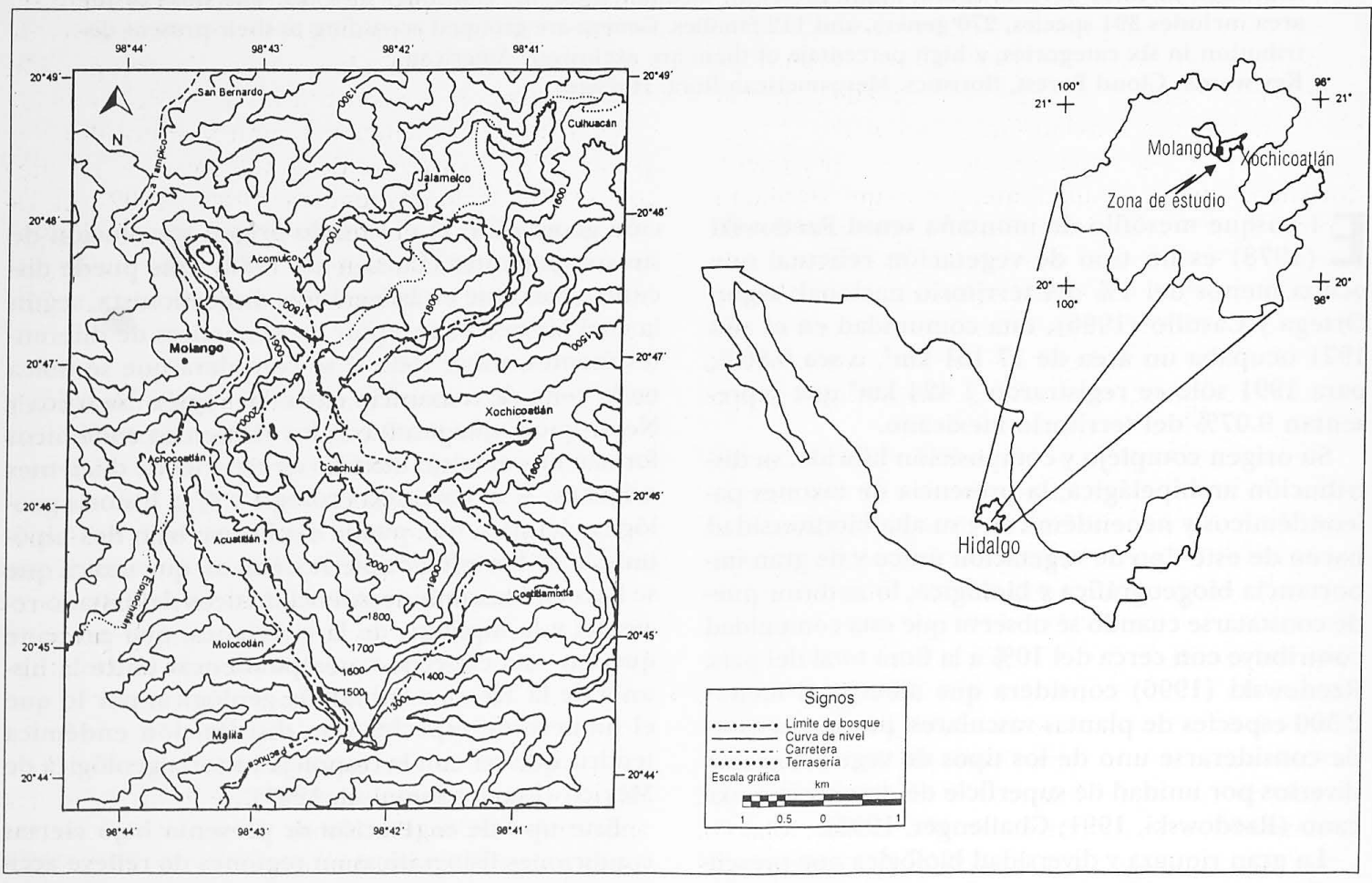

Figura 1. Localización del área de estudio. 
Los estudios del bosque mesófilo de montaña en el estado de Hidalgo y más específicamente de la región de la Huasteca Hidalguense son escasos; son pioneros el de Miranda y Sharp (1950), quienes describen someramente la vegetación de Chapulhuacán, Tutotepec, Tenango de Doria, Tianguistengo y Zacualtipán, el de Paray (1949) la de Agua Blanca, Cumbre de Muridores, San Bartolo, Cerro de la Campana y Tenango de Doria y el de Puig (1976) quien describe las formaciones vegetales de Tenango de Doria, Tlahuelompa y Tlanchinol, además de efectuar algunos muestreos en Molango, Atezca, Jalamelco, Malila y Xochicoatlán. Recientemente se han publicado listas más exhaustivas de Tlanchinol (Luna et al., 1994) y Tenango de Doria (Alcántara y Luna, 1997).

Los bosques mesófilos de montaña poseen una gran diversidad de especies, riqueza importante por sí misma y por ser un patrimonio de las nuevas generaciones, lo que debe estimular su conservación y la búsqueda de métodos adecuados para aprovecharlo de manera sostenida. Sin embargo, estas comunidades han sido perturbadas desde hace varios siglos por actividades humanas tales como la forestal, la agrícola, la ganadera y el fuego; la extensión de tales disturbios es tan grande en estas regiones que la vegetación original está desapareciendo rápidamente (Luna et al., 1988), por lo que su área de distribución se ha reducido en 20 años para 1991 a menos de una décima parte $(8.3 \%)$, a una tasa promedio de $0.787 \mathrm{~km}^{2}$ por año, como lo señalan Ortega y Castillo (1996).

No obstante que se ha avanzado en el conocimiento florístico, este no es suficiente, por lo que resulta urgente conocer mejor la composición florística de este tipo de vegetación e inventariar las diferentes asociaciones del bosque mesófilo de montaña en México, reconocer las relaciones y los patrones de distribución de los taxones en esta comunidad, así como efectuar comparaciones con algunas localidades equivalentes en México.

El presente trabajo pretende contribuir al conocimiento de la composición florística de los bosques mesófilos de montaña del estado de Hidalgo, y en general de México, comentando algunos aspectos sobre su composición taxonómica y distribución.

\section{Área de estudio}

Localización y ruta de acceso. La zona de estudio comprende parte de dos municipios de la zona norte del estado de Hidalgo: Molango y Xochicoatlán (figura 1), ambos pertenecientes a la región de Molango, entre los paralelos $20^{\circ} 41^{\prime}$ y $20^{\circ} 58^{\prime} \mathrm{N}$ y los mericlianos $98^{\circ} 35^{\prime}$ y $98^{\circ} 52^{\prime} \mathrm{O}$. Colinda al norte con los municipios de Lolotla, Tepehuacán de Guerrero y
Calnali; al sur con el de Metztitlán; al oeste con Tlahuiltepa, Juárez-Hidalgo y Eloxochitlán y al este con Tianguistengo y Zacualtipán.

$\mathrm{El}$ acceso a la zona de estudio es por la carretera federal 85 México-Pachuca con una desviación en la carretera federal 105 Pachuca-Tampico; en el km 122 hay una brecha de acceso, que corresponde a la ranchería de Molocotlán, ubicada a $10 \mathrm{~km}$ al sur (sobre la carretera) de Molango. Molango cuenta con una aeropista para vuelos locales e interestatales.

El nombre Molango deriva de las raíces nahuas molli, "mole" y co, "lugar de", "lugar de mole". Su nombre primitivo fue el de Molanco, el cual es traducido por algunos autores como "Lugar de Dios Mola", y se encontraba unido al señorío de Tenochtitlán. Sin embargo otras versiones sostienen que Molango fue fundado por los chichimecas (CEEMH, 1988). Xochicoatlán deriva de las raíces nahuas xochitl, "flor" y cuauhtl, "árbol", "árbol de flores"; éste se llamó en sus orígenes Xochicuautitlán, que significa en náhuatl "liquidambar". Fue fundado por indios nahuas en el año 608 a.C. (CEEMH, 1988).

Fisiografía. Molango y Xochicoatlán pertenecen a la subprovincia de las Llanuras y Sierras de Querétaro e Hidalgo y a la Subprovincia del Carso Huasteco; sin embargo los rasgos más importantes de la zona de estudio corresponden a la segunda. En esta porción dominan las sierras y constituyen la región conocida como Huasteca Hidalguense, donde se localizan la mayoría de los sistemas de topoformas clasificados como valle de laderas tendidas (INEGI, 1992). La variación altitudinal del terreno va de 1405 a 2200 msnm, teniendo una ladera de gran extensión con exposición oeste y otra más de exposición sur, así como pequeñas cañadas.

Hidrografía. Los municipios se encuentran dentro de la región hidrológica Río Pánuco, dentro de la cuenca del Río Moctezuma (INEGI, 1992). Los ríos que cruzan el municipio de Xochicoatlán son el Chinameca, Tecamachal y Xoconta y al de Molango el Claro, Xoltetla, Pilateno y Agua Fría; en este último se encuentra la Laguna de Atezca (CEemh, 1988). Otros riachuelos menores y escurrentías se encuentran en la zona de estudio, los que desembocan al Río Molocotlán afluente del Río Malila.

Geología. La zona corresponde a la provincia de la Sierra Madre Oriental, donde afloran las rocas más antiguas de México (Precámbrico), así como una secuencia estratigráfica muy completa de rocas paleozoicas, mesozoicas y cenozoicas, que en conjunto forman un grupo rocoso con más de $4000 \mathrm{~m}$ de espesor. Las rocas 
son principalmente sedimentarias continentales y marinas; las calizas son las más ampliamente distribuidas y constituyen el cuerpo principal de la Sierra Madre Oriental (INEGI, 1992). La Formación Huayacocotla es la que predominantemente aflora en el área, seguida de la Formación Tepexic; la primera pertenece al Jurásico Temprano, específicamente a la edad Sinemuriano y Pliensbachiano y la segunda al Jurásico Medio, específicamente a la edad Caloviano a la que también pertenece la Formación Cahuasas (Ochoa-Camarillo, 1997). La zona está comprendida dentro de lo que se denomina "La Región de Molango", la que estructuralmente pertenece a la parte central del anticlinorio de Huayacocotla, del cinturón de pliegues y cabalgaduras de la Sierra Madre Oriental (Ochoa-Camarillo, 1997), es por ello que esta unidad sedimentaria está representada morfológicamente por montañas altas con cantiles verticales y cañones profundos (INEGI, 1992). En términos de geología económica se le conoce como Distrito Manganesífero de Molango (Ochoa-Camarillo, 1997).

Clima. La parte baja de la zona de estudio (1450-1990 $\mathrm{msnm}$ ) se caracteriza por presentar un clima templado,

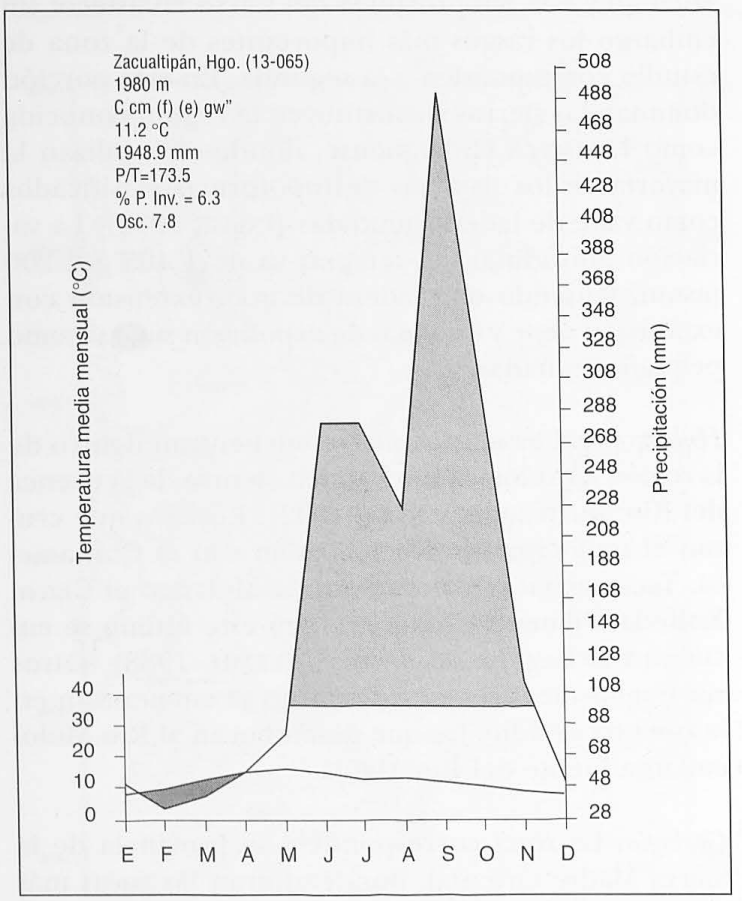

Figura 2. Diagrama ombrotérmico de Zacualtipán, Hgo., zona aledaña al área de estudio y representativa de altitudes superiores de $1052000 \mathrm{~m}$. con diferencias en cuanto a condiciones de humedad. La zona oeste posee un clima templado subhúmedo, con temperatura media anual entre 12 y $18^{\circ} \mathrm{C}$, temperatura media del mes más frío entre -3 y $18^{\circ} \mathrm{C}$ y la del mes más caliente mayor de $6.5^{\circ} \mathrm{C}$, régimen de lluvias de verano, el más húmedo de los subhúmedos (cociente precipitación anual/temperatura anual mayor de 55), de tipo $\mathrm{C}(\mathrm{w} 2)$ (CONABIO-Estadigrafía, 1997). La zona este posee un clima templado húmedo con régimen de lluvias de verano, porcentaje de lluvia de invierno mayor de 10.2, oscilación anual de las temperaturas mensuales extremosa (entre $7 \mathrm{y}$ $14^{\circ} \mathrm{C}$ ), marcha de temperaturas tipo ganges (mes más caliente antes de junio), de tipo $\mathrm{C}(\mathrm{m})$ (f) (e)g (García, 1988; ConABio-Estadigrafía, 1997).

El área de estudio también presenta sitios con altitudes superiores a los $2000 \mathrm{~m}$, en donde las condiciones térmicas disminuyen. La estación Zacualtipán es la más cercana a Molocotlán; posee un clima semifrío húmedo, con temperatura media anual entre 5 y $12^{\circ} \mathrm{C}$, temperatura media del mes más frío entre -3 y $18^{\circ} \mathrm{C}$ y la del mes más caliente mayor de $6.5^{\circ} \mathrm{C}$, régimen de lluvias intermedio, mes más seco con más de $40 \mathrm{~mm}$, porcentaje de precipitación mensual mayor de 18, con canícula, oscilación anual de temperaturas extremosa y marcha anual de temperaturas tipo ganges, Cc(f) (e)gw" (García, 1988; CONABIo-Estadigrafía, 1997). Debido a que esta estación cuenta con datos actualizados, fue utilizada para elaborar la gráfica ombrotérmica (figura 2) que representa el clima del área de estudio a esta altitud (Dra. María Engracia Hernández, com. pers.)

Suelo. Los suelos tienen textura de migajón-arenoso con una rica capa de hojarasca y gran cantidad de materia orgánica en forma de humus, por lo que generalmente son de color obscuro. Son comunes entre los suelos las rendzinas asociadas a Feozem calcárico, los Feozem calcáricos asociado a Fluvisol calcáricos en fase pedregosa y los Litosoles (INEGI, 1992).

A pesar del reducido uso agrícola que presentan los suelos debido a lo abrupto del terreno, se practica la agricultura seminómada representada principalmente por el cultivo de maíz y frijol. Muchas de las áreas también se encuentran sometidas a una intensa explotación por la extracción de madera para uso local, además del establecimiento de potreros con fines ganaderos, principalmente bovinos.

\section{Método}

La elección del área de estudio se hizo con base en visitas preliminares del área, revisión de mapas (INEGI 1989, 1993) y fotografías aéreas (CETENAL, 1976), 
con el fin de efectuar observaciones sobre el relieve en general, las vías de comunicación y los caminos de acceso, buscando que fueran sitios poco alterados por actividades humanas.

Se efectuaron 11 salidas de campo, de junio de 1996 a agosto de 1997, en todas las estaciones y en casi todos los meses del año. Los especímenes botánicos (fanerógamas y pteridofitas) se recolectaron preferentemente en estado fértil (floración y/o fructificación) y se obtuvieron datos pertinentes para describir cualitativamente la comunidad y realizar los perfiles esquemáticos de las asociaciones. (figura 3).

Los especímenes se determinaron en lo posible hasta el nivel de especie, a veces con ayuda de especialistas; éstas se realizaron en el Herbario de la Facultad de Ciencias (FCME) y los ejemplares se depositaron en el mismo herbario.

Se obtuvo una lista florística del área, la cual fue ordenada alfabéticamente, tomando como base el sistema de clasificación de Engler y Diels (1936) para Angiospermae y Gymnospermae y el de Mickel y Beitel (1988) para Pteridophyta y grupos afines. Las autoridades taxonómicas se abreviaron de acuerdo con
Brummitt y Powell (1992). La distribución actual de los géneros de plantas vasculares fue revisada con base en los trabajos de Willis (1973) y Mabberley (1997).

\section{Caracterización del bosque}

El bosque mesófilo de montaña de Molocotlán se caracteriza en general por ser fisonómicamente denso, compuesto por tres estatos arbóreos: uno alto (19-30 $\mathrm{m})$, uno medio $(8-19 \mathrm{~m})$ y uno bajo $(2-8 \mathrm{~m})$, además de un arbustivo y un herbáceo. Otras formas de vida bien representadas son los bejucos y epífitas. Algunos árboles, principalmente los del estrato arbóreo alto, pierden parcialmente sus hojas en la estación seca y fría del año, como Liquidambar, Cercis y varias especies de encinos.

La zona donde se desarrolla el bosque incluye un intervalo altitudinal de los 1450 a los $2200 \mathrm{msnm}$ y presenta pendientes de ligeras a abruptas que llegan a formar relieves muy accidentados e inaccesibles; las variaciones en altitud, orientación y relieve determinan cambios florístico-fisonómicos. Básicamente se reconocen dos asociaciones, además de comunidades

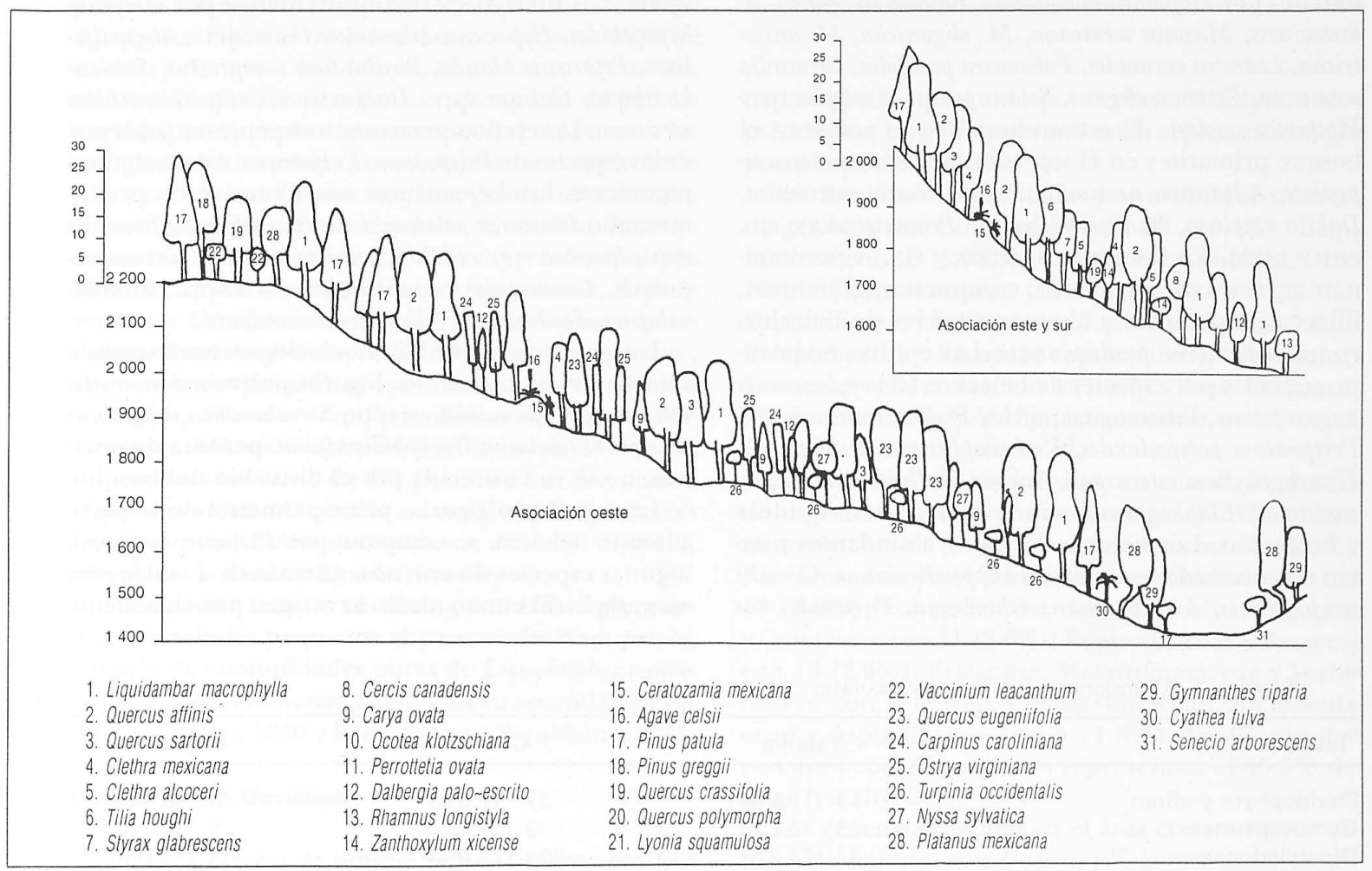

Figura 3. Perfiles esquemáticos de las asociaciones presentes en el área de estudio. 
cercanas a ríos, y propias de cañadas protegidas.

La primera asociación se distribuye en la zona oeste del área; presenta un relieve poco accidentado y se caracteriza por ser fisonómicamente semidensa y relativamente homogénea con respecto a la asociación de la zona este. En ella se presentan tres estratos arbóreos bien definidos: uno alto (19-30 m), en donde predominan individuos de Liquidambar macrophylla y Quercus affinis; ambas especies se distribuyen en todo el gradiente altiltudinal, principalmente en altitudes superiores a los $1800 \mathrm{~m}$, donde son más frecuentes. Generalmente estos taxones se entremezclan con otras especies de encinos, principalmente con Quercus eugeniifolia y $Q$. sartorii y pinos como Pinus patula y $P$. greggii. En el estrato arbóreo medio $(8-19 \mathrm{~m})$ son comunes Carpinus caroliniana, Ostrya virginiana, Carya ovata, Befaria laevis, Clethra mexicana y Nyssa sylvatica; en este estrato, en altitudes de 1550 a $1650 \mathrm{~m}$, es común Pinus oocarpa. En el estrato arbóreo bajo (2-8 m) son conspicuas Turpinia occidentalis y Perrottetia ovata, junto con otros taxones que pueden ser parte también del estrato arbustivo como Microtropis schiedeana, Rondeletia capitellata, Oreopanax xalapensis y Solanum aligerum. El estrato arbustivo es pobre y está representado por Hoffmannia montana, Randia xalapensis, $R$. laetevirens, Miconia mexicana, M. oligotricha, $M$. anisotricha, Leandra cornoides, Palicourea padifolia, Bernardia mexicana, Cestrum elegans, Solanum ssp., Acalypha sp. y Pipthrotix areolaris. El estrato herbáceo es pobre en el bosque primario y en él son comunes Chamaedorea tepejilote, Adiantum andicola, Archibaccharis intermedia, Dahlia coccinea, Sanicula liberta y Prionosciadium sp., entre otras. En las zonas abiertas y claros predominan especies de solanȧceas, compuestas, gramíneas, liliáceas, ciperáceas y algunas especies de helechos como Lophosoria quadripinnata. Las epífitas están representadas por especies de helechos (Campyloneurum angustifolium, Vittaria graminifolia, Phelbodium areolatum, Polypodium polypodioides, P. rhodopleuron, Pecluma sp., Hymenophyllum ectocarpon, Anemia phyllitidis, Adiantum andicola y Elaphoglossum spp.), además de orquídeas y bromelias. Los bejucos son muy abundantes y están representados por Solanum appendiculatum, Clematis acapulcensis, Archibaccharis schiedeana, Parthenocissus quinquefolia, Vitis bourgaeana, Toxicodendron radicans, Gonolobus macranthus, Bomarea acutifolia e Ipomoea spp.

La segunda asociación se distribuye en la laderas con exposición sur y este, en un relieve más accidentado. Esta se caracteriza por ser fisonómicamente densa y heterogénea, siendo menos clara la estratificación arbórea, aunque los árboles más altos y robustos pertenecen a Liquidambar macrophylla y varias especies en encinos. Inmediatamente debajo de ellas se distinguen especies de tamaño medio como Clethra mexicana, C. alcoceri, Tilia houghi, Styrax glabrescens, Rhamnus capreaefolia, Morus celtidifolia, Cercis canadensis, Carya ovrata, Befaria laevis y Dalbergia palo-escrito, en tre otras. El estrato arbóreo bajo está representado por Rondeletia capitellata, Zanthoxylum xicense, Viburnum ciliatum, V. tiliafolium, Ocotea klotzschiana, Perrottetia ovata y Rhamnus longistyla, además de Cornus excelsa y $C$. disciflora en los lugares más abiertos. En el estrato arbustivo, que en algunos lugares llega a mezclarse con el estrato arbóreo bajo, se presentan Leandra cornoides, Miconia spp., Bernardia mexicana, Picramnia xalapensis, Triumfetta acrantha, T. grandiflora, Zapoteca portoricensis, Senna septentrionalis, Oxalis rhombifolia, Ageratina hidalgensis, Piptothrix areolaris y Deppea obtusiflora. Las hierbas están representadas por Ascyrum hypericoides, Hypericum silenoides, Desmodium angustifolium, Peperomia blanda, Phyllanthus compressus, Sanicula liberta, Galium spp., Dahlia coccinea y Tibouchina mexicana. Las epífitas se encuentran representadas por varias especies de Polypodium, Encyclia, así como algunas piperáceas. Los bejucos son muy abundantes, predominando Dioscorea nelsonii, Celastrus pringlei, Bomarea spp., Ipomoea spp., Philadelphus mexicanus, Cobaea stipularis, Cissampelos tropaeolifolia, Vitis spp., Matelea velutina, Smilax spp. y Valeriana scandens.

Las parásitas en ambas asociaciones son escasas y sólo son frecuentes en los lugares perturbados; entre ellas están: Phoradendron spp., Struthanthus deppeanus y Cuscuta tinctoria; Conopholis alpina, parásita de encinos, no se ve favorecida por el disturbio del bosque.

La vegetación riparia, principalmente de la parte suroeste del área, se compone por Platanus mexicana, algunas especies de encinos, además de Liquidambar macrophylla. El estrato medio lo ocupan principalmente

Cuadro 1. Abundancia de plantas vasculares.

\begin{tabular}{lrrr}
\hline Taxón & Familia & Género & Especie \\
\hline Pteridophyta y afines & $13(11.6 \%)$ & $21(7.8 \%)$ & 33 \\
Gymnospermae & $3(2.7 \%)$ & $3(1.1 \%)$ & $5.4 \%)$ \\
Dicotyledonae & $82(73.2 \%)$ & $208(77.0 \%)$ & $305(78.0 \%)$ \\
Monocotyledonae & $14(12.5 \%)$ & $38(14.1 \%)$ & $48(12.3 \%)$ \\
Total & 112 & 270 & 391 \\
\hline
\end{tabular}


Gymnanthes riparia, Juglans mollis y Acer negundo, y el estrato bajo Senecio arborescens y Cyathea fulva. Entre los arbustos son frecuentes Piper chamissonis, Leandra cornoides, Kohleria deppeana, Miconia ssp., Piper ssp., además de una laurácea no determinada. Las hierbas más frecuentes son labiadas (Hyptis mutabilis, Ocimum sellowii, Salvia involucrata, S. mexicana) y Xanthosoma robustum. Las epífitas más comunes son Vittaria graminifolia, Hymenophyllum ectocarpon y Polypodium spp. Entre los bejucos destaca Melothria pendula y Bomarea spp.

El piso altitudinal de los 1850 a $2200 \mathrm{~m}$ es relativamente menos húmedo que el resto del bosque; en él predominan especies heliófitas como Pinus patula, P. greggii, Quercus crassifolia, Q. polymorpha, Lyonia squamulosa, Vaccinium leucanthum, Xylosma flexuosum, Baccharis heterophylla, B. conferta, Gaultheria spp. y Chimaphila maculata.

En los afloramientos rocosos y húmedos son frecuentes Agave celsii, Ceratozamia mexicana, Cuphea calaminthifolia, Pinguicula moranensis y Begonia spp.

Entre las especies favorecidas por un disturbio moderado del bosque están: Solandra guttata, Athenae viscosa, Cyphomandra betacea, Annona cherimola, Selaginella spp., Lycopodium clavatum, Drymaria villosa, $\mathrm{Hy}$ pericum silenoides, Phyllanthus compressus, Mikania micrantha, Piqueria trinervia, Senecio salignus, Viguiera cordata y Vernonia leiboldeana, entre otras. Otras son claramente favorecidas por un alto grado de perturbación, por ejemplo algunas especies comunes en las orillas de los caminos como Amaranthus spp., Asclepias curassavica, Lobelia laxiflora, Sambucus mexicana, Gibasis geniculata, Euphorbia hirta, E. dentata, Pinaroppapus roseus, Cyperus mutisii, Carex chordalis, Buddleia cordata, Anoda cristata, Malvaviscus arboreus, Lopezia racemosa, Oenothera rosea, O. tetraptera, Argemone grandiflora, Bocconia frutescens, Passiflora spp., Rubus spp., Bouvardia ternifolia, Castilleja arvensis, Verbena litoralis, V. elegans, Solanum erianthum, Bidens odorata, Florestina pedata, Aldama dentata, Baccharis trinervis, Trixis inula y Erytrina americana; en los potreros son frecuentes Hypoxis mexicana, Crocosmia crocosmiflora, Orthrosanthus chimboracensis, Echeandia mexicana, Plantago australis, Phaseolus coccineus y Rynchelytrum repens.

Dentro del bosque se distinguen áreas reforestadas con árboles pequeños al parecer de Pinus patula, además de comunidades puras de Liquidambar macrophylla que seguramente son de origen secundario (Miranda y Sharp, 1950 y Pennington y Sarukhán, 1998).

\section{Composición florística}

La flora de la zona de estudio está compuesta por 112 familias, 270 géneros y 391 especies (Apéndice 1). Las dicotiledóneas son el grupo mejor representado ( $78 \%$
Cuadro 2. Abundancia de géneros/especies por familia (con cinco o más especies) en la zona de estudio.

\begin{tabular}{lrr}
\hline Familia & $\begin{array}{c}\text { Número de } \\
\text { géneros/especies } \\
\text { 270/391 }\end{array}$ & Porcentaje \\
\hline Compositae & $28 / 44$ & $10.4 / 11.3$ \\
Leguminosae & $16 / 22$ & $5.9 / 5.6$ \\
Solanaceae & $8 / 18$ & $3.0 / 4.6$ \\
Rubiaceae & $11 / 16$ & $4.1 / 4.1$ \\
Labiatae & $7 / 13$ & $2.6 / 3.3$ \\
Orchidaceae & $11 / 13$ & $4.1 / 3.3$ \\
Polypodiaceae & $5 / 12$ & $1.8 / 3.1$ \\
Fagaceae & $1 / 11$ & $0.4 / 2.8$ \\
Gramineae & $8 / 11$ & $3.0 / 2.8$ \\
Euphorbiaceae & $7 / 10$ & $2.6 / 2.6$ \\
Rosaceae & $5 / 10$ & $1.8 / 2.6$ \\
Ericaceae & $4 / 6$ & $1.5 / 1.5$ \\
Melastomataceae & $3 / 6$ & $1.1 / 1.5$ \\
Verbenaceae & $3 / 6$ & $1.1 / 1.5$ \\
Amaryllidaceae & $3 / 5$ & $1.1 / 1.3$ \\
Asclepiadaceae & $5 / 5$ & $1.8 / 1.3$ \\
Aspleniaceae & $2 / 5$ & $0.7 / 1.3$ \\
95 familias restantes & $143 / 178$ & $53.0 / 45.5$ \\
\hline
\end{tabular}

de las especies), seguido por las monocotiledóneas y pteridofitas; las gimnospermas están representadas por pocas especies (cuadro 1).

Las familias representadas por un mayor número de géneros son Compositae con 28 (10.4\%), Leguminosae con 16 (5.9\%), Orchidaceae y Rubiaceae con $11(4.1 \%)$, Gramineae y Solanaceae con $8(3.0 \%)$, Euphorbiaceae y Labiatae con 7 (2.6\%), Asclepiadaceae, Polypodiaceae y Rosaceae con 5 (1.8\%), Cyperaceae, Ericaceae y Malvaceae con 4 (1.5\%) y Amaryllidaceae, Melastomataceae y Verbenaceae, entre otras, con 3 $(1.1 \%)$, cada una (cuadro 2 ).

Las familias más abundantes en cuanto a número de especies son Compositae con 44 (11.3\%), Leguminosae con $22(5.6 \%)$, Solanaceae con $18(4.6 \%)$, Rubiaceae con 16 (4.1\%), Labiatae y Orchidaceae con $13(3.3 \%)$, Polypodiaceae con $12(3.1 \%)$, Fagaceae y Gramineae con 11 (2.8\%), Euphorbiaceae y Rosaceae con $10(2.6 \%)$, Ericaceae, Melastomataceae y Verbenaceae con $6(1.5 \%)$ y Amaryllidaceae, Asclepiadaceae y Aspleniaceae con 5 (1.3\%); las 95 familias restantes con 178 especies representan el $45.5 \%$ del total (cuadro 2).

Los géneros presentes en el área con un mayor número de especies son Quercus y Solanum con 11 especies, Polypodium con 8 y Salvia con 7; algunos otros taxones importantes pueden revisarse en el cuadro 3. 
De los 270 géneros representados en Molocotlán, 52 son árboles, 47 arbustos, 129 hierbas, 11 epífitas, 27 bejucos y 4 parásitas. Algunos taxones presentan más de una forma de vida, por lo que se ubicaron en aquella donde eran más frecuentes en el área (cuadro 4). A nivel de especie, las hierbas son las más abundantes $(172,44.0 \%)$, seguidas por los árboles (76, $19.4 \%)$, los arbustos $(74,18.9 \%)$, los bejucos $(43$, $11.0 \%)$, las epífitas $(21,5.4 \%)$ y las parásitas $(5,1.3 \%)$ (figura 4).

\section{Distribución}

Análisis de géneros por categoría geográfica. Los 270 géneros se agruparon, de acuerdo con su distribución actual, en seis categorías (figura 5): 98 géneros $(36.3 \%)$ se distribuyen exclusivamente en América, $63(23.3 \%)$ en las zonas tropicales y subtropicales del mundo, $40(14.8 \%)$ son de amplia distribución, 33

Cuadro 3. Géneros con tres o más especies en la flora de Molocotlán.

\begin{tabular}{lll}
\hline Géneros & $\begin{array}{c}\text { Número de } \\
\text { especies (391) }\end{array}$ & Porcentaje \\
\hline
\end{tabular}

\begin{tabular}{lrr} 
Quercus & 11 & 2.8 \\
Solanum & 11 & 2.8 \\
Polypodium & 8 & 2.0 \\
Salvia & 7 & 1.8 \\
Elaphoglossum & 4 & 1.0 \\
Euphorbia & 4 & 1.0 \\
Senecio & 4 & 1.0 \\
Aster & 3 & 0.8 \\
Baccharis & 3 & 0.8 \\
Begonia & 3 & 0.8 \\
Bouvardia & 3 & 0.8 \\
Crotalaria & 3 & 0.8 \\
Encyclia & 3 & 0.8 \\
Eupatorium & 3 & 0.8 \\
Galium & 3 & 0.8 \\
Ipomoea & 3 & 0.8 \\
Lantana & 3 & 0.8 \\
Lasiacis & 3 & 0.8 \\
Miconia & 3 & 0.8 \\
Pinus & 3 & 0.8 \\
Polygonum & 3 & 0.8 \\
Rubus & 3 & 0.8 \\
Tillandsia & 3 & 0.8 \\
Vernonia & 3 & 0.8 \\
Viguiera & 3 & 0.8 \\
Vitis & 3 & 0.8 \\
Zanthoxylum & 32 & 0.8 \\
243 géneros restantes & & \\
\hline & & \\
\hline
\end{tabular}

$(12.2 \%)$ en el hemisferio norte, $26(9.6 \%)$ en los trópicos y $10(3.7 \%)$ en las zonas templadas y subtropicales.

Los 98 géneros americanos, a su vez, se distribuyen en el continente de la siguiente manera: 42 géneros lo hacen en los trópicos, 15 de Norteamérica (principalmente sur de Estados Unidos) a Centroamérica-norte de Sudamérica, 11 en los trópicos y subtrópicos, 9 son de amplia distribución, 7 subtropicales, 4 son propios del Hemisferio norte, 6 son endémicos o cuasiendémicos a México (propios de Megaméxico 2 en el sentido de Rzedowski, 1991), 3 se distribuyen de México a Sudamérica y uno en zonas templadas y subtropicales.

Análisis de géneros por forma de vida. En la figura 5 se puede revisar la presencia de géneros de acuerdo con su forma de vida y categoría geográfica. De los 52 géneros de árboles presentes en Molocotlán, 18 se distribuyen principalmente en el hemisferio norte, 15 en los trópicos y subtrópicos, 8 en los trópicos, 6 se distribuyen exclusivamente en el continente americano (Lozanella, Myrcianthes y Rondeletia en los trópicos, Befaria en los trópicos y subtrópicos, Gymnanthes de Norteamérica a Centroamérica y Cnidosculus de amplia distribución), 3 son de amplia distribución (Ilex, Vaccinium y Zanthoxylum) y 2 son propios de áreas templadas y subtropicales (Acer y Sambucus).

De los 47 géneros de arbustos representados en la zona de estudio, 27 son exclusivos del continente americano (Ceratozamia y Piptothrix son cuasiendémicos a México), 7 se distribuyen en los trópicos, 6 son de amplia distribución, 6 habitan los trópicos y subtrópicos y uno es propio del hemisferio norte.

De un total de 129 géneros de hierbas registradas para el área, 43 se distribuyen exclusivamente en América (Loxothysanus y Prionosciadium son endémicos a México y Gibasis es preferentemente mexicano), 34 son tropicales y subtropicales, 27 de amplia distribución, 11 habitan preferentemente el hemisferio norte, 8 los trópicos y 6 las zonas templadas y subtropicales.

En el área se presentan 11 géneros de epífitas, de las cuales 7 son americanas, 2 de amplia distribución (Polypodium y Phlebodium), una tropical (Pleopeltis) y otra tropical y subtropical (Vittaria).

De los 27 géneros de bejucos, 12 son americanos, 7 tropicales y subtropicales, 3 del hemisferio norte (Gelsemium, Philadelpus y Vitis), 2 tropicales (Canavalia y Cissampelos) 2 de zonas templadas y subtropicales (Clematis y Parthenocissus) y uno de amplia distribución (Valeriana).

De las 4 parásitas presentes, 3 son americanas y una de amplia distribución. 


\section{Discusión y conclusiones}

No se tiene conocimiento de trabajos florísticos o vegetacionales previos para la zona de estudio; Puig (1976) quien trabajó los bosques de la Huasteca, sólo cita algunas especies de zonas aledañas al área. El bosque de Molocotlán posee una flora rica y diversa constituida por 391 especies de plantas vasculares, representando el $13.0 \%$ de la riqueza florística estimada para este tipo de vegetación en México (Rzedoswki, 1991).

Descle un punto de vista ecológico y considerando aspectos fisonómico-estructurales y florísticos, se reconocen en general dos asociaciones vegetales determinadas básicamente por el clima (diferencias en el grado de humedad y temperatura) y la orografía (relieve y exposición de la ladera). Una tercera asociación ocupa el piso altitudinal de los 1850 a 2200 msnm, en donde la temperatura es más baja y donde se establecen especies más heliófitas como Pinus y varias especies de Ericaceae. No obstante, una caracterización del bosque mesofilo de montaña debe tomar en cuenta su complejidad histórica y geográfica además de la ecológica.

De las familias que Rzedowski (1996) cita que prosperan preferentemente en esta comunidad, en Molocotlán se presentan las siguientes: Aceraceae, Aquifoliaceae, Begoniaceae, Burmaniaceae, Clethraceae, Cornaceae, Cyatheaceae, Gesneriaceae, Gleicheniaceae, Hymenophyllaceae, Lauraceae, Lycopodiaceae, Myricaceae, Myrsinaceae, Orchidaceae, Piperaceae, Selaginellaceae, Staphyleaceae, Styracaceae y Theaceae, esto es, el $60.6 \%$. En Molocotlán es notoria la ausencia de representantes de la familia Magnoliaceae, misma que en bosques adyacentes (Tlanchinol, Tlahuelompa, Eloxochitlán) es frecuente. Las familias más abundantes en cuanto a número de especies y géneros son Compositae, Leguminosae, Solanaceae, Rubiaceae, Labiatae y Orchidaceae. Los géneros con mayor número de especies son Quercus, Solanum, Polypodium y Salvia, entre otros.

Algunos géneros de árboles cuantitativamente importantes en el bosque de Molocotlán son: Alnus, Carpinus, Carya, Clethra, Cleyera, Cornus, Dalbergia, Dendropanax, Juglans, Liquidambar; Meliosma, Nyssa, Oreopanax, Persea, Prunus, Quercus, Styrax y Ternstroemia, mismos que son característicos de este tipo de vegetación.

Algunas especies de distribución restringida y/o en peligro de extinción que se presentan en el área son: Carya palmeri, Ceratozamia mexicana, Elaphoglossum obscurum, Dalbergia palo-escrito, Diospyros riojae, Juglans mollis, Litsea glaucescens, Loxothysanus pedunculatus y Tibouchina galeottiana. Otras especies consideradas

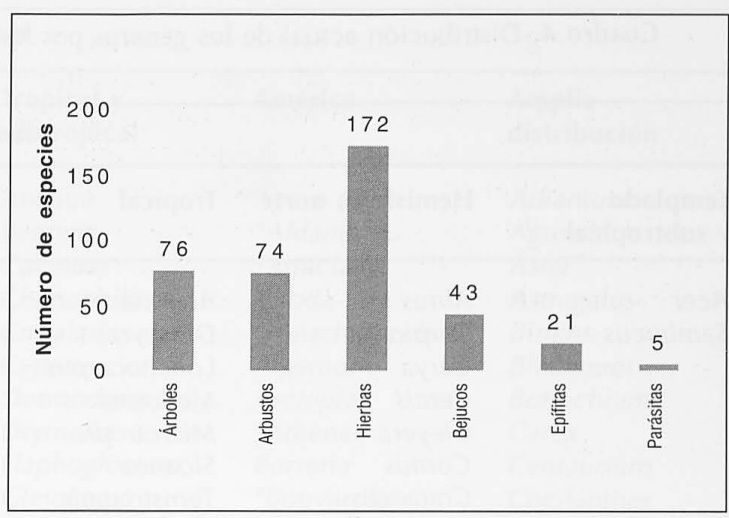

Figura 4. Abundancia de especies por formas de vida.

como raras, amenazadas o sujetas a protección especial por la Norma Oficial Mexicana (Dirección General de Regulación Ambiental, 1998) son Bouvardia xylosteoides, Carpinus caroliniana, Cyathea fulva y Stanhopea tigrina.

Los géneros de plantas vasculares presentes en el área tienen una distribución actual principalmente en los trópicos y subtrópicos de América, principalmente los géneros de arbustos, árboles bajos y hierbas. Los árboles altos tienen una distribución principalmente norteña.

Al igual que otros bosques montanos, el bosque de Molocotlán se encuentra sometido a fuertes presiones humanas (extracción de madera, agricultura y ganadería); se cultiva principalmente maíz y frijol y se mantiene ganado vacuno. Es frecuente encontrar tocones, individuos jóvenes y renuevos de Dalbergia palo-escrito, árbol de madera preciosa que en Molocotlán se extrae para la elaboración de muebles. La tala de árboles altos es muy evidente para la obtención de leña. En ciertas zonas hay indicios de reforestación con pino.

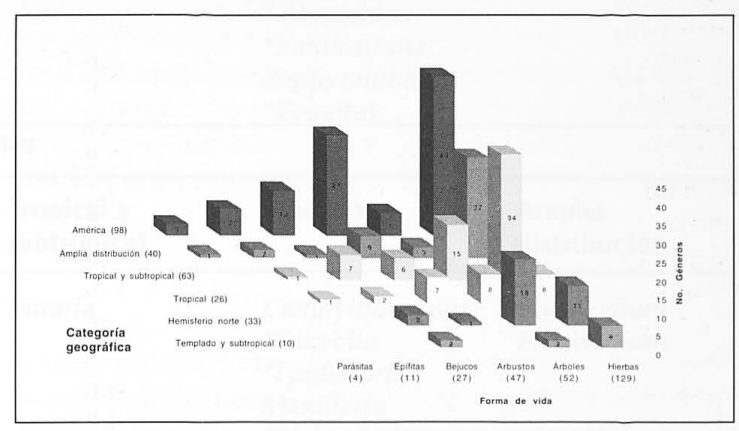

Figura 5. Abundancia de géneros por forma de vida y categoría geográfica. 
Rafael Mayorga Saucedo, Isolda luna Vega y Othón Alcántara Ayala

Cuadro 4. Distribución actual de los géneros por forma de vida.

\begin{tabular}{|c|c|c|c|c|c|}
\hline \multicolumn{6}{|c|}{ Árboles } \\
\hline $\begin{array}{l}\text { Templado } \\
\text { y subtropical }\end{array}$ & Hemisferio norte & Tropical & $\begin{array}{l}\text { Tropical y } \\
\text { subtropical }\end{array}$ & América & $\begin{array}{l}\text { Amplia } \\
\text { distribución }\end{array}$ \\
\hline $\begin{array}{l}\text { Acer } \\
\text { Sambucus }\end{array}$ & $\begin{array}{l}\text { Alnus } \\
\text { Carpinus } \\
\text { Carya } \\
\text { Cercis } \\
\text { Cleyera } \\
\text { Cornus } \\
\text { Crataegus } \\
\text { Juglans } \\
\text { Liquidambar } \\
\text { Lyonia } \\
\text { Nyssa } \\
\text { Ostrya } \\
\text { Pinus } \\
\text { Platanus } \\
\text { Prunus } \\
\text { Quercus } \\
\text { Tilia } \\
\text { Viburnum }\end{array}$ & $\begin{array}{l}\text { Annona } \\
\text { Diospyros } \\
\text { Lonchocarpus } \\
\text { Meliosma } \\
\text { Microtropis } \\
\text { Sloanea } \\
\text { Ternstroemia } \\
\text { Trichilia }\end{array}$ & $\begin{array}{l}\text { Buddleia } \\
\text { Clethra } \\
\text { Cyathea } \\
\text { Dalbergia } \\
\text { Dendropanax } \\
\text { Erythrina } \\
\text { Morus } \\
\text { Ocotea } \\
\text { Perrottetia } \\
\text { Podocarpus } \\
\text { Rhamnus } \\
\text { Ricinus } \\
\text { Styrax } \\
\text { Trema } \\
\text { Turpinia }\end{array}$ & $\begin{array}{l}\text { Befaria } \\
\text { Cnidosculus } \\
\text { Gymnanthes } \\
\text { *Lozanella } \\
\text { *Myrcianthes } \\
\text { *Rondeletia }\end{array}$ & $\begin{array}{l}\text { llex } \\
\text { Vaccinium } \\
\text { Zanthoxylum }\end{array}$ \\
\hline \multicolumn{6}{|c|}{ Arbustos } \\
\hline $\begin{array}{l}\text { Templado } \\
\text { y subtropical }\end{array}$ & Hemisferio norte & Tropical & $\begin{array}{l}\text { Tropical y } \\
\text { subtropical }\end{array}$ & América & $\begin{array}{l}\text { Amplia } \\
\text { distribución }\end{array}$ \\
\hline & Eupatorium & $\begin{array}{l}\text { Acalypha } \\
\text { Lantana } \\
\text { Litsea } \\
\text { Miconia } \\
\text { Piper } \\
\text { Triumfetta } \\
\text { Xylosma }\end{array}$ & $\begin{array}{l}\text { Fuchsia } \\
\text { Gaultheria } \\
\text { Gordonia } \\
\text { Rapanea } \\
\text { Urera } \\
\text { Vernonia }\end{array}$ & $\begin{array}{l}\text { Ageratina } \\
\text { Baccharis } \\
\text { Bernardia } \\
\text { Bocconia } \\
\text { Brickellia } \\
\text { *Ceratozamia } \\
\text { *Cestrum } \\
\text { Citharexylum } \\
\text { *Cyphomandra } \\
\text { Datura } \\
\text { Deppea } \\
\text { Fleischmannia } \\
\text { Hoffmannia } \\
\text { *Kohleria } \\
\text { *Leandra } \\
\text { *Malvaviscus } \\
\text { Monnina } \\
\text { *Oreopanax } \\
\text { *Palicourea } \\
\text { *Peltostigma } \\
\text { *Picramnia } \\
\text { **Piptothrix } \\
\text { Randia } \\
\text { Trixis } \\
\text { Verbesina } \\
\text { Viguiera } \\
\text { Zapoteca }\end{array}$ & $\begin{array}{l}\text { Myrica } \\
\text { Oxalis } \\
\text { Rubus } \\
\text { Senecio } \\
\text { Senna } \\
\text { Solanum }\end{array}$ \\
\hline
\end{tabular}


Florística del bosque mesófilo de montaña de Molocotlán, Molango-Xochicoatlán, Hidalgo, México

\section{Hierbas}

\begin{tabular}{|c|c|c|c|c|c|}
\hline $\begin{array}{l}\text { Templado } \\
\text { y subtropical }\end{array}$ & Hemisferio norte & Tropical & $\begin{array}{l}\text { Tropical y } \\
\text { subtropical }\end{array}$ & América & $\begin{array}{l}\text { Amplia } \\
\text { distribución }\end{array}$ \\
\hline $\begin{array}{l}\text { Amaranthus } \\
\text { Ascyrum } \\
\text { Linum } \\
\text { Melilotus } \\
\text { Trifolium } \\
\text { Stachys }\end{array}$ & $\begin{array}{l}\text { Agrimonia } \\
\text { Alchemilla } \\
\text { Arenaria } \\
\text { Castilleja } \\
\text { Mitchella } \\
\text { Monotropa } \\
\text { Pinguicula } \\
\text { Prunella } \\
\text { Ranunculus } \\
\text { Rumex } \\
\text { Woodwardia }\end{array}$ & $\begin{array}{l}\text { Acmella } \\
\text { Mikania } \\
\text { Crocosmia } \\
\text { Lasiacis } \\
\text { Oplismenus } \\
\text { Piqueria } \\
\text { Rhynchelytrum } \\
\text { Setaria }\end{array}$ & $\begin{array}{l}\text { Anemia } \\
\text { Begonia } \\
\text { Calanthe } \\
\text { Chimaphila } \\
\text { Crotalaria } \\
\text { Cyperus } \\
\text { Desmodium } \\
\text { Drymaria } \\
\text { Elaphoglossum } \\
\text { Gleichenia } \\
\text { Habenaria } \\
\text { Hieracium } \\
\text { Hymenophyllum } \\
\text { Hypericum } \\
\text { Hypoxis } \\
\text { Hyptis } \\
\text { Iresine } \\
\text { Kyllinga } \\
\text { Lobelia } \\
\text { Lycopodium } \\
\text { Ocimum } \\
\text { Orthrosanthus } \\
\text { Panicum } \\
\text { Pavonia } \\
\text { Peperomia } \\
\text { Phyllanthus } \\
\text { Phytolacca } \\
\text { Pilea } \\
\text { Salvia } \\
\text { Selaginella } \\
\text { Sida } \\
\text { Tagetes } \\
\text { Thalictrum } \\
\text { Verbena }\end{array}$ & $\begin{array}{l}\text { Agave } \\
\text { *Aldama } \\
\text { *Amicia } \\
\text { Anoda } \\
\text { ***Archibaccharis } \\
\text { Argemone } \\
\text { Asclepias } \\
\text { *Athenae } \\
\text { Borreria } \\
\text { *Bouvardia } \\
\text { *Centropogon } \\
\text { *Chamaedorea } \\
\text { *Coccocypselum } \\
\text { Crusea } \\
\text { Cuphea } \\
\text { Dahlia } \\
\text { *Dictyostega } \\
\text { *Dichaea } \\
\text { Echeandia } \\
\text { Florestina } \\
\text { Galinsoga } \\
\text { **Gibasis } \\
\text { *Govenia } \\
\text { Heuchera } \\
\text { *Homolepis } \\
\text { Jaltomata } \\
\text { Laennecia } \\
\text { Lepechinia } \\
\text { ***Lopezia } \\
\text { *Lophosoria } \\
\text { **Loxothysanus } \\
\text { Monarda } \\
\text { Oenothera } \\
\text { Pecluma } \\
\text { Pinaropappus } \\
\text { **Prionosciadium } \\
\text { Schiedeella } \\
\text { Spigelia } \\
\text { Stevia } \\
\text { *Tibouchina } \\
\text { *Xanthosoma } \\
\text { Zephyranthes } \\
\text { *Zeugites } \\
\end{array}$ & $\begin{array}{l}\text { Adiantum } \\
\text { Agrostis } \\
\text { Aster } \\
\text { Astragalus } \\
\text { Bidens } \\
\text { Blechnum } \\
\text { Botrychium } \\
\text { Carex } \\
\text { Centaurium } \\
\text { Cheilanthes } \\
\text { Equisetum } \\
\text { Erigeron } \\
\text { Euphorbia } \\
\text { Galium } \\
\text { Geranium } \\
\text { Juncus } \\
\text { Lythrum } \\
\text { Malaxis } \\
\text { Physalis } \\
\text { Plantago } \\
\text { Polygala } \\
\text { Polygonum } \\
\text { Polystichum } \\
\text { Rhynchospora } \\
\text { Sanicula } \\
\text { Stellaria } \\
\text { Urtica }\end{array}$ \\
\hline \multicolumn{6}{|c|}{ Epífitas } \\
\hline \multirow[t]{2}{*}{$\begin{array}{l}\text { Templado } \\
\text { y subtropical }\end{array}$} & Hemisferio norte & Tropical & $\begin{array}{l}\text { Tropical y } \\
\text { subtropical }\end{array}$ & América & $\begin{array}{l}\text { Amplia } \\
\text { distribución }\end{array}$ \\
\hline & & Pleopeltis & Vittaria & $\begin{array}{l}\text { Campyloneurum } \\
\text { *Encyclia } \\
\text { *Epidendrum } \\
\text { Maxillaria } \\
\text { *Pleurothallis } \\
\text { *Stanhopea } \\
\text { *Tillandsia }\end{array}$ & $\begin{array}{l}\text { Polypodium } \\
\text { Phlebodium }\end{array}$ \\
\hline
\end{tabular}




\section{Bejucos}

\begin{tabular}{|c|c|c|c|c|c|}
\hline $\begin{array}{l}\text { Templado } \\
\text { y subtropical }\end{array}$ & Hemisferio norte & Tropical & $\begin{array}{l}\text { Tropical y } \\
\text { subtropical }\end{array}$ & América & $\begin{array}{l}\text { Amplia } \\
\text { distribución }\end{array}$ \\
\hline $\begin{array}{l}\text { Clematis } \\
\text { Parthenocissus }\end{array}$ & $\begin{array}{l}\text { Gelsemium } \\
\text { Philadelphus } \\
\text { Vitis }\end{array}$ & $\begin{array}{l}\text { Canavalia } \\
\text { Cissampelos }\end{array}$ & $\begin{array}{l}\text { Celastrus } \\
\text { Dioscorea } \\
\text { Ipomoea } \\
\text { Passiflora } \\
\text { Sarcostemma } \\
\text { Smilax } \\
\text { Toxicodendron }\end{array}$ & $\begin{array}{l}\text { *Bomarea } \\
\text { Centrosema } \\
\text { *Cologania } \\
\text { *Cobaea } \\
\text { Gonolobus } \\
\text { *Matelea } \\
\text { Melothria } \\
\text { Nyctocereus } \\
\text { *Oxypetalum } \\
\text { Phaseolus } \\
\text { Serjania } \\
\text { *Solandra }\end{array}$ & Valeriana \\
\hline \multicolumn{6}{|c|}{ Parásitas } \\
\hline $\begin{array}{l}\text { Templado } \\
\text { y subtropical }\end{array}$ & Hemisferio norte & Tropical & $\begin{array}{l}\text { Tropical y } \\
\text { subtropical }\end{array}$ & América & $\begin{array}{l}\text { Amplia } \\
\text { distribución }\end{array}$ \\
\hline & & & & $\begin{array}{l}\text { Conopholis } \\
\text { *Phoradendron } \\
\text { *Struthanthus }\end{array}$ & Cuscuta \\
\hline
\end{tabular}

\footnotetext{
* distribución tropical, ** endémico o cuasiendémico de México, y *** de México a Centroamérica.
}

\section{Agradecimientos}

Se agradece a las siguientes personas su ayuda en la determinación del material: Mario Sousa y Ramiro Cruz (leguminosas), Abisaí García (amarilidáceas), Martha Martínez (euforbiáceas), José Luis Villaseñor y Miguel Luna (compuestas), Alejandro Miranda (gramíneas), Nelly Diego (ciperáceas), Susana Valencia (fagáceas), Gerardo Salazar (orquídeas) y Mónica Palacios Ríos (helechos y grupos afines). La Dra. María Engracia Hernández corrigió amablemente la parte de clima de este trabajo. El Dr: Zoltán DeCserna nos facilitó la actualización de la carta geológica del área. Dos árbitros ayudaron a mejorar sustancialmente el manuscrito. Este trabajo fue financiado por el proyecto IN215798 de PAPIT y parcialmente por el L091 de CONABIO.

\section{Literatura Citada}

Alcántara O. y Luna I. 1997. Florística y análisis biogeográfico del bosque mesófilo de montaña de Tenango de Doria, Hidalgo, México. Anales del Instituto de Biología. Universidad Nacional Autónoma de México Serie Botánica 68(2):57-106.
Brummitt R. K. y Powell C.E. (Editores) 1992. Authors of plant names. Royal Botanic Gardens, Kew. Great Britain. 732 pp.

CEEMH (Centro Estatal de Estudios Municipales de Hidalgo). 1988. Los municipios de Hidalgo. Colección Enciclopédica de los Municipios de México. México. 303 pl).

CETEnal (Centro de Estudios clel Territorio Nacional). 1976. Fotografías aéreas. Z IIA. 1:50000. Feb 76. DF 152,31. R-246. L-18.

Challenger A. 1998. La zona ecológica templada húmeda (bosque mesófilo de montaña). En: Utilización y conservación de los ecosistemas terrestres de México. Pasado, presente y futuro. CONABIO-Instituto de Biología, UNAM-Sierra Madre. México. pp. 443-518.

Dirección General de Regulación Ambiental. 1998. Listado de especies de plantas y hongos que se encuentran en la Norma Oficial Mexicana (NOM-ECOL-050-94). Disponible en www.ine.gob.mx/normas/rec_nat/ plannom.htm.

Engler A. y Diels L. 1936. Syllabus der Pflanzenfamilien. $11^{3}$. Berlin.

García E. 1988. Modificaciones al sistema de clasificación climática de Köppen. Instituto de Geografía, UNAM. México. $217 \mathrm{pp}$.

CONABIO-Estadigrafía. 1997. Carta de climas México. Sis- 
tema de Köppen modificado por E. García. Escala 1:1,000,000. México.

INEGI (Instituto Nacional de Estadística, Geografía e Informática). 1989. Carta topográfica Molango, F14D51, 1:50000.

INEGI (Instituto Nacional de Estadística, Geografía e Informática). 1993. Carta topográfica Metztitlán, F14D61, 1:50000.

INEGI (Instituto Nacional de Estadística, Geografía e Informática). 1992. Síntesis geográfica del estado de Hidalgo. México. 134 pp.

Luna I. y Espinosa D. 1993. Biodiversidad, biogeografía y taxonomía: las perspectivas para el estudio de la geografía de las plantas en México. Libro de resúmenes, XII Congreso Mexicano de Botánica, Mérida, Yucatán. 295 pp.

Luna I., Almeida L. y Llorente J. 1989. Reconocimiento florístico y consicleraciones fitogeográficas del bosque mesófilo de montaña de las cañadas de Ocuilan, estados de Morelos y México. Anales Instituto de Biología. Universidad Nacional Autónoma de México Serie Botánica 59(1):63-87.

Luna I., Almeida L., Villers L. y Lorenzo L. 1988. Reconocimiento florístico y consideraciones fitogeográficas del bosque mesófilo de montaña de Teocelo, Veracruz. Boletín de la Sociedad Botánica de México 48:35-63.

Luna I., Ocegueda S. y Alcántara O. 1994. Florística y notas biogeográficas del bosque mesófilo de montaña del municipio de Tlanchinol, Hidalgo, México. Anales Instituto de Biología. Universidad Nacional Autónoma de México Serie Botánica 65(1):31-62.

Mabberley D.J. 1997. The plant-book. A portable dictionary of the vascular plants. Cambridge University Press. Great Britain. 858 pp.

Mickel J. y Beitel J.M. 1988. Pteridophyte Flora of Oaxa- ca, México. Memoires of the New York Botanical Garden 46:1-566 pp.

Miranda F. y Sharp A.J. 1950. Characteristics of the vegetation in certain temperate regions of eastern Mexico. Ecology 31:313-333.

Ochoa-Camarillo H.R. 1997. Geología del anticlinorio de Huayacocotla en la región de Molango, Hgo., México. Instituto de Investigaciones en Ciencias de la Tierra de la Universidad Nacional Autónoma del Estado de Hidalgo e Instituto de Geología de la Universidad Nacional Autónoma de México, II Convención sobre la Evolución Geológica de México y Recursos Asociados, Pachuca, Hgo., Libro-guía de las excursiones geológicas, Excursión 1, p 1-17.

Ortega E.F. y Castillo G. 1996. El bosque mesófilo de montaña y su importancia forestal. Ciencias 43:32-39.

Paray L. 1949. Exploraciones en el estado de Hidalgo. Boletín de la Sociedad Botánica de México 8:1-7.

Pennington T.D. y Sarukhán J. 1998. Árboles tropicales de México. Universidad Nacional Autónoma de MéxicoFondo de Cultura Económica. México. 521 pp.

Puig, H. 1976. Végétation de la Huasteca, Mexique. Mission Archéologique et Ethonologique Francaise au Mexique. México. $531 \mathrm{pp}$.

Rzedowski J. 1978. Vegetación de México. Ed. Limusa. México. 423 pP.

Rzedowski J. 1991. Diversidad y orígenes de la flora fanerogámica de México. Acta Botánica Mexicana 14:3-21.

Rzedowski J. 1996. Análisis preliminar de la flora vascular de los bosques mesófilos de montaña de México. Acta Botánica Mexicana 35:25-44

Willis J.C. 1973. A dictionary of the flowering plants and ferns. Eighth edition. Cambridge at the University Press. Cambridge, Great Britain. 1245 pp. 
Apéndice 1. Lista florística del bosque mesófilo de montaña de Molocotlán, Hgo.

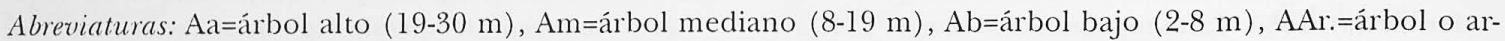
busto, $\mathrm{Ar}=$ arbusto, $\mathrm{EAr}=$ arbusto epífito, $\mathrm{H}=$ hierba, $\mathrm{Be}=$ bejuco, $\mathrm{Ep}=$ epífita y $\mathrm{P}=$ parásita.

\section{PTERIDOPHYTA Y GRUPOS AFINES}

\section{ADIANTACEAE}

Adiantum andicola Liebm. $(\mathrm{H})$

Cheilanthes aff. cuneata Link $(\mathrm{H})$

Vittaria graminifolia Kaulf. (Ep)

\section{ASPLENIACEAE}

Elaphoglossum obscurum (Fourn.) C.Chr. (H)

Elaphoglossum sartorii (Liebm.) Mickel $(\mathrm{H})$

Elaphoglossum spp. ( $\mathrm{H})$

Polystichum hartwegii (Klotzsch) Hieron. (H)

\section{BLECHNACEAE}

Blechnum schiedeanum (Schltdl. ex Presl) Hieron. (H)

Woodwardia martinezii Maxon $(\mathrm{H})$

Woodwardia X semicordata Mickel et Beitel (H)

\section{CYATHEACEAE}

Cyathea fulva (M.Martens et Galeotti) Fée (Ab)

Cyathea aff. fulva (M.Martens et Galeotti) Fée (Ab)

\section{EQUISETACEAE}

Equisetum myriochaetum Schltdl. et Cham. (H)

\section{GLEICHENIACEAE}

Gleichenia bancroftii Hook.

\section{HYMENOPHYLLACEAE}

Hymenophyllum ectocarpon Fée $(\mathrm{H})$

\section{LOPHOSORIACEAE}

Lophosoria quadripinnata (Gmelin) C.Chr. $(\mathrm{H})$

\section{LYCOPODIACEAE}

Lycopodium clavatum L. $(\mathrm{H})$

\section{OPHIOGLOSSACEAE}

Botrychium dissectum Spreng. ssp. decompositum (M.Martens et Galeotti) R.T.Clausen (H)

\section{POLYPODIACEAE}

Campyloneurum angustifolium (Sw.) Fée (Ep)

Pecluma sp. (H)

Phlebodium areolatum (Humb. et Bonpl.) J.Sm. (Ep)

Pleopeltis crassinervata (Fée) Moore (Ep)

Polypodium aff. cryptocarpon Fée (Ep)

Polypodium furfuraceum Schltdl. et Cham. (Ep)
Polypodium aff. martensii Mett. (H)

Polypodium plebeium Schltdl. et Cham. (Ep)

Polypodium polypodioides (L.) Watt. (Ep)

Polypodium rhodopleuron Kunze $(\mathrm{H})$

Polypodium spp. (Ep y H)

\section{SCHIZAEACEAE}

Anemia phyllitidis (L.) Sw. (H)

SELAGINELLACEAE

Selaginella wrightii Hieron. (H)

Selaginella sp. $(\mathrm{H})$

\section{GYMNOSPERMAE}

\section{CYCADACEAE}

Ceratozamia mexicana Brongn. (Ar)

\section{PINACEAE}

Pinus greggii Engelm. ex Parl. (Aa)

Pinus oocarpa Schiede ex Schltdl. (Am)

Pinus patula Schiede et Deppe ex Schltdl. et Cham. (Aa)

\section{PODOCARPACEAE}

Podocarpus reichei Buchholz et Gray (Ab)

\section{ANGIOSPERMAE}

\section{ACERACEAE}

Acer negundo L. ssp. mexicana (DC.) Wesm. (Am)

AGAVACEAE

Agave celsii Hook. $(\mathrm{H})$

\section{AMARANTHACEAE}

Amaranthus hybridus L. (H)

Amaranthus sp. $(\mathrm{H})$

Iresine diffusa Humb. et Bonpl. ex Willd. (H)

Iresine interrupta Benth. (Be)

\section{AMARYLLIDACEAE}

Bomarea acutifolia (Link et Otto) Herb. (Be)

Bomarea edulis (Tussac) Herb. (Be)

Hypoxis mexicana Schult.f. (H)

Zephyranthes brevipes (Baker ex Donn.Sm.) Standl. (H)

Zephyranthes lindleyana Herb. (H) 
ANACARDIACEAE

Toxicodendron radicans (L.) Kuntze (Be)

ANNONACEAE

Annona cherimola Mill. (Ab)

AQUIFOLIACEAE

Ilex discolor Hemsl. (AAr)

ARACEAE

Xanthosoma robustum Schott $(\mathrm{H})$

\section{ARALIACEAE}

Dendropanax arboreus (L.) Decne. et Planch. (Am)

Oreopanax flaccidus Marchal (EAr)

Oreopanax xalapensis (Kunth) Decne. et Planch. (AAr)

\section{ASCLEPIADACEAE}

Asclepias curassavica L. $(\mathrm{H})$

Gonolobus macranthus Kunze (Be)

Matelea velutina (Schltdl.) Woodson $(\mathrm{Be})$

Oxypetalum cordifolium (Vent.) Schltr. (Be)

Sarcostemma elegans Decne. (Be)

\section{BEGONIACEAE}

Begonia incarnata Link et Otto $(\mathrm{H})$

Begonia spp. (H)

\section{BETULACEAE}

Alnus acuminata Kunth ssp. arguta (Schltdl.) Furlow (Am)

Carpinus caroliniana Walter (Am)

Ostrya virginiana (Mill.) K.Koch (Am)

\section{BROMELIACEAE}

Tillandsia spp. (Ep)

\section{BURMANIACEAE}

Dictyostega orobanchoides (Hook.) Miers $(\mathrm{H})$

\section{CACTACEAE}

Nyctocereus oaxacensis Britton et Rose (Be)

\section{CAMPANULACEAE}

Centropogon grandidentatus (Schltdl.) Zahlbr. $(\mathrm{H})$

Lobelia laxiflora Kunth var. laxiflora $(\mathrm{H})$

\section{CAPRIFOLIACEAE}

Sambucus mexicana C.Presl ex DC. (Ab)

Viburnum ciliatum Greenm. (Ab)

Viburnum tiliaefolium (Oerst.) Hemsl. (AAr)

\section{CARYOPHYLLACEAE}

Arenaria lanuginosa (Michx.) Rohrb. (H)
Drymaria villosa Cham. et Schltdl. $(\mathrm{H})$

Stellaria ovata Willd. ex Schltdl. (H)

\section{CELASTRACEAE}

Celastrus pringlei Rose (Be)

Microtropis occidentalis Loes. (Ab)

Microtropis schiedeana Loes. (AAr)

Perrottetia ovata Hemsl. (Ab)

\section{CLETHRACEAE}

Clethra alcoceri Greenm. (Am)

Clethra mexicana A.DC. (Am)

\section{COMMELINACEAE}

Gibasis geniculata (Jacq.) Rohweder $(\mathrm{H})$

\section{COMPOSITAE}

Acmella oppositifolia (Lam.) R.K.Jansen var. oppositifolia $(\mathrm{H})$

Ageratina hidalgensis (B.L.Rob.) R.M.King et H.Rob. (Ar)

Ageratina ligustrina (DC.) R.M.King et H.Rob. (Ar)

Aldama dentata La Llave var. dentata $(\mathrm{H})$

Archibaccharis intermedia (S.F.Blake) B.L.Turner (H)

Archibaccharis schiedeana (Benth.) J.D.Jackson (Be)

Aster subulatus Michx. (H)

Aster spp. (H)

Baccharis conferta Kunth (Ar)

Baccharis heterophylla Kunth (Ar)

Baccharis trinervis (Lam.) Pers. (Ar)

Bidens odorata Cav. $(\mathrm{H})$

Brickellia secundiflora (Lag.) A.Gray (Ar)

Dahlia coccinea Cav. $(\mathrm{H})$

Erigeron karvinskianus DC. $(\mathrm{H})$

Eupatorium spp. (Ar)

Fleischmannia pycnocephala (Less.) R.M.King et

H.Rob. (Ar)

Florestina pedata (Cav.) Cass. $(\mathrm{H})$

Galinsoga parviflora Cav. $(\mathrm{H})$

Hieracium abscissum Less. (H)

Laennecia sophiifolia (Kunth) G.L.Nesom (H)

Loxothysanus pedunculatus Rydb. (H)

Mikania micrantha Kunth (H)

Pinaroppapus roseus (Less.) Less. ( $\mathrm{H})$

Piptothrix areolaris (DC.) R.M.King et H.Rob. (Ar)

Piqueria trinervia Cav. $(\mathrm{H})$

Senecio arborescens Steetz $(\mathrm{Ab})$

Senecio salignus DC. (Ar)

Senecio spp. (Ar)

Stevia sp. $(\mathrm{H})$

Tagetes micrantha Cav. $(\mathrm{H})$

Trixis inula Crantz (Ar)

Verbesina spp. (Ar)

Vernonia leiboldiana Schltdl. (Ar)

Vernonia spp. (Ar) 
Viguiera cordata (Hook. et Arn.) D'Arcy (Ar) Viguiera spp. ( $\mathrm{H}$ y $\mathrm{Be})$

\section{CONVOLVULACEAE}

Cuscuta tinctoria Mart. ex Engelm. (P)

Ipomoea purga (Wender.) Hayne (Be)

Ipomoea purpurea (L.) Roth (Be)

Ipomoea sp. (Be)

\section{CORNACEAE}

Cornus disciflora Moc. et Sessé ex DC. (Ab)

Cornus excelsa Kunth (AAr)

\section{CUCURBITACEAE}

Melothria pendula L. (Be)

CYPERACEAE

Carex chordalis Liebm. (H)

Cyperus mutisii (Kunth) Andersson $(\mathrm{H})$

Killinga odorata Vahl $(\mathrm{H})$

Rhynchospora radicans (Schltdl. et Cham.) H.Pfeiff. ssp.

radicans $(\mathrm{H})$

\section{DIOSCOREACEAE}

Dioscorea nelsonii Uline ex R.Knuth (Be)

\section{EBENACEAE}

Diospyros riojae Gómez Pompa (Ab)

\section{ELAEOCARPACEAE}

Sloanea sp. (Ab)

\section{ERICACEAE}

Befaria laevis Benth. (Am)

Gaultheria hirtiflora Benth. (Ar)

Gaultheria odorata Bredem. ex Willd. (Ar)

Lyonia squamulosa M.Martens et Galeotti (Ab)

Vaccinium leucanthum Cham. et Schltdl. (Ab)

Vaccinium sp. (Ab)

\section{EUPHORBIACEAE}

Acalypha sp. (Ar)

Bernardia mexicana Müll.Arg. (Ar)

Cnidosculus multilobus (Pax) I.M.Johnst. (Ab)

Euphorbia dentata Michx. (H)

Euphorbia aff. graminea Jacq. $(\mathrm{H})$

Euphorbia hirta L. (H)

Euphorbia nutans Lag. (H)

Gymnanthes riparia (Schltdl.) Klotzsch (Am)

Phyllanthus compressus Kunth $(\mathrm{H})$

Ricinus communis $\mathrm{L}$. (Ab)

\section{FAGACEAE}

Quercus affinis Scheidw. (Aa)
Quercus castanea Née (Ab)

Quercus crassifolia Humb. et Bonpl. (Am)

Quercus diversifolia Née (Am)

Quercus eduardii Trel. (Ab)

Quercus eugeniifolia Liebm. (Aa)

Quercus germana Schltdl. et Cham. (Aa)

Quercus glabrescens Benth. (Am)

Quercus laeta Liebm. (Ab)

Quercus aff. polymorpha Schltdl. et Cham. (Aa)

Quercus sartorii Liebm. (Aa)

FLACOURTIACEAE

Xylosma flexuosum (Kunth) Hemsl. (Ar)

GENTIANACEAE

Centaurium chironioides (Griseb.) Druce $(\mathrm{H})$

GERANIACEAE

Geranium semannii Peyr. (H)

GESNERIACEAE

Kohleria deppeana (Schltdl. et Cham.) Fritsch (Ar)

\section{GRAMINEAE}

Agrostis perennans (Walter) Tuck. $(\mathrm{H})$

Homolepis glutinosa (Sw.) Zuloaga et Soderstr. (H)

Lasiacis divaricata (L.) Hitchc. $(\mathrm{H})$

Lasiacis procerrima (Hack.) Hitchc. $(\mathrm{H})$

Lasiacis rugelii (Griseb.) Hitchc. var. rugelii $(\mathrm{H})$

Oplismenus hirtellus (L.) P. Beauv. ssp. setarius (Lam.)

Mez ex Ekman (H)

Panicum laxiflorum Lam. $(\mathrm{H})$

Panicum sellowii Nees (H)

Rhynchelytrum repens (Willd.) C.E.Hubb. (H)

Setaria scandens Schrad. ex Schult. (H)

Zeugites americana Willd. var. mexicana (Kunth)

McVaugh $(\mathrm{H})$

\section{GUTTIFERAE}

Ascyrum hypericoides L. $(\mathrm{H})$

Hypericum philonotis Cham. et Schltdl. $(\mathrm{H})$

Hypericum silenoides Juss. var. silenoides $(\mathrm{H})$

HAMAMELIDACEAE

Liquidambar macrophylla Oerst. (Aa)

\section{IRIDACEAE}

Crocosmia crocosmiiflora (Lemoine ex E.Morren) N.E.Br: (H)

Orthrosanthus chimboracensis (Kunth) Baker var. exsertus R.C.Foster (H)

JUGLANDACEAE

Carya ovata (Mill.) K. Koch var. mexicana (Engelm. ex 
Hemsl.) W.E.Manning (Am)

Carya palmeri W.E.Manning (Am)

Juglans mollis Engelm. (Am)

\section{JUNCACEAE}

Juncus sp. (H)

\section{LABIIATAE}

Hyptis mutabilis (Rich.) Briq. (H)

Lepechinia schiedeana (Schltdl.) Vatke $(\mathrm{H})$

Monarda fistulosa L. var. mollis (L.) Benth. (H)

Ocimum sellowiii Benth. (H)

Prunella vulgaris $\mathrm{L} .(\mathrm{H})$

Salvia gracilis Benth. $(\mathrm{H})$

Salvia helianthemifolia Benth. $(\mathrm{H})$

Salvia involucrata Cav. $(\mathrm{H})$

Salvia aff. laevis Benth. $(\mathrm{H})$

Salvia mexicana Sessé et Moc. $(\mathrm{H})$

Salvia plurispicata Epling $(\mathrm{H})$

Salvia sp. (H)

Stachys boraginoides Cham. et Schltdl. (H)

\section{LAURACEAE}

Litsea glaucescens Kunth Ar.

Ocotea klotzschiana (Nees) Hemsl. (Ab)

\section{LEGUMINOSAE}

Amicia zygomeris DC. $(\mathrm{H})$

Astragalus hypoleucus S.Schauer $(\mathrm{H})$

Canavalia hirsuta (M.Martens et Galeotti) Standl. (Be)

Canavalia sp. (Be)

Centrosema pubescens Benth. (Be)

Cercis canadensis $\mathrm{L}$. (Am)

Cologania congesta Rose (Be)

Cologania glabior Rose (Be)

Crotalaria pumila Ortega $(\mathrm{H})$

Crotalaria rotundifolia Walter ex J.F.Gmel. var. vulgaris Windler $(\mathrm{H})$

Crotalaria sp. $(\mathrm{H})$

Dalbergia palo-escrito Rzed. et Guridi-Gómez (Am)

Desmodium angustifolium (Kunth) DC. (H)

Desmodium sp. (H)

Erythrina americana (Dryander) Mill. (Ab)

Lonchocarpus sp. (Ab)

Melilotus indica (L.) All. (H)

Phaseolus coccineus L. (Be)

Senna pendula (Humb. et Bonpl. ex Willd.) H.S.Irwin et Barneby (Ar)

Senna septentrionalis (Viviani) H.S.Irwin et Barneby (Ar)

Trifolium repens $\mathrm{L}$. $(\mathrm{H})$

Zapoteca portoricensis (Jacq.) H.M.Hern. ssp. portoricensis (Ar)

\section{LENTIBULARIACEAE}

Pinguicula moranensis Kunth $(\mathrm{H})$
LILIACEAE

Echeandia mexicana Cruden $(\mathrm{H})$

Smilax mollis Humb. et Bonpl. ex Willd. (Be)

Smilax tomentosa Kunth (Be)

LINACEAE

Linum nelsonii Rose $(\mathrm{H})$

LOGANIACEAE

Buddleia cordata Kunth (Ab)

Gelsemium sempervirens (L.) J.St.-Hil. (Be)

Spigelia longiflora M.Martens et Galeotti (H)

LORANTHACEAE

Phoradendron falcatum (Cham. et Schltdl.) Trel. (P)

Phoradendron sp. (P)

Struthanthus deppeanus (Schltdl. et Cham.) Blume (P)

LYTHRACEAE

Cuphea calaminthifolia Schltdl. (H)

Lythrum gracile Benth. $(\mathrm{H})$

\section{MALVACEAE}

Anoda cristata (L.) Schltdl. (H)

Malvaviscus arboreus Cav. var. arboreus (Ar)

Pavonia uniflora (Sessé et Moc.) Fryxell (H)

Sida rhombifolia $\mathrm{L}$. $(\mathrm{H})$

\section{MELASTOMATACEAE}

Leandra cornoides (Schltdl. et Cham.) Cogn. (Ar)

Miconia anisotricha (Schltdl.) Triana (Ar)

Miconia mexicana (Bonpl.) Naudin (Ar)

Miconia oligotricha (DC.) Naudin (Ar)

Tibouchina galeottiana $\operatorname{Cogn} .(\mathrm{H})$

Tibouchina mexicana (G.Don) Cogn. (H)

\section{MELIACEAE}

Trichilia havanensis Jacq. (Ab)

MENISPERMACEAE

Cissampelos tropaeolifolia DC. (Be)

MORACEAE

Morus celtidifolia Kunth (Am)

MYRICACEAE

Myrica cerifera L. (Ar)

MYRSINACEAE

Rapanea myricoides (Schltdl.) Lundell (AAr)

\section{MYRTACEAE}

Myrcianthes fragrans (Sw.) McVaugh var. fragrans (Ab) 
NYSSACEAE

Nyssa sylvatica Marshall (Am)

ONAGRACEAE

Fuchsia arborescens Sims (Ar)

Lopezia racemosa Cav. ssp. racemosa $(\mathrm{H})$

Oenothera rosea L'Hér. $(\mathrm{H})$

Oenothera tetraptera Cav. $(\mathrm{H})$

\section{ORCHIDACEAE}

Calanthe calanthoides (A.Rich. et Galeotti) Hamer et Garay (H)

Dichaea glauca (Sw.) Lindl. $(\mathrm{H})$

Encyclia aff. candollei (Lindl.) Schltr. (Ep)

Encyclia cyanocolumna (Ames, F.T.Hubb. et C.Schweinf.)

Dressler (Ep)

Encyclia polybulbon (Sw.) Dressler (Ep)

Epidendrum longipetalum A.Rich. et Galeotti (Ep)

Govenia liliacea (La Llave et Lex.) Lindl. (H)

Habenaria clypeata Lindl. (H)

Malaxis soulei L.O.Williams $(\mathrm{H})$

Maxillaria aff. meleagris Lindl. (Ep)

Pleurothallis ornata (Garay) Foldats (Ep)

Schiedeella transversalis (A. Rich et Galeotti) Schltr. (H)

Stanhopea tigrina Bateman et Lindl. (Ep)

\section{OROBANCHACEAE}

Conopholis alpina Liebm. (P)

OXALIDACEAE

Oxalis rhombifolia Jacq. (Ar)

Oxalis sp. (H)

PALMAE

Chamaedorea tepejilote Liebm. (H)

\section{PAPAVERACEAE}

Argemone grandiflora Sweet ssp. grandiflora $(\mathrm{H})$

Bocconia frutescens L. (Ar)

\section{PASSIFLORACEAE}

Passiflora sicyoides Schltdl. et Cham. (Be)

Passiflora subpeltata Ortega (Be)

\section{PHYTOLACCACEAE}

Phytolacca purpurascens A.Braun et Bouché $(\mathrm{H})$

Phytolacca rugosa A.Braun et Bouché $(\mathrm{H})$

\section{PIPERACEAE}

Peperomia blanda (Jacq.) Kunth $(\mathrm{H})$

Peperomia ovatum (Mig.) Kunth (Ep)

Piper auritum Kunth (Ar)

Piper chamissonis (Miq.) Steud. (Ar)
PLANTAGINACEAE

Plantago australis Lam. $(\mathrm{H})$

\section{PLATANACEAE}

Platanus mexicana Moric. var. mexicana (Aa)

POLEMONIACEAE

Cobaea stipularis Benth. (Be)

\section{POLYGALACEAE}

Monnina xalapensis Kunth ( $\mathrm{Ar}$ )

Polygala sp. (H)

\section{POLYGONACEAE}

Polygonum lapathifolium $\mathrm{L}$. $(\mathrm{H})$

Polygonum punctatum Elliot $(\mathrm{H})$

Polygonum sp. $(\mathrm{H})$

Rumex conglomeratus Murray $(\mathrm{H})$

\section{PYROLACEAE}

Chimaphila maculata (L.) Pursh (H)

Monotropa uniflora $\mathrm{L} .(\mathrm{H})$

\section{RANUNCULACEAE}

Clematis acapulcensis Hook. et Arn. (Be)

Ranunculus dichotomus Moc. et Sessé ex DC. $(\mathrm{H})$

Thalictrum pubigerum Benth. $(\mathrm{H})$

\section{RHAMNACEAE}

Rhamnus capreaefolia Schltdl. var. matudai L.A.Johnston et M.C.Jonhston (Am)

Rhamnus longistyla C.B.Wolf (Ab)

\section{ROSACEAE}

Agrimonia macrocarpa (Focke ex Donn.Sm.) Rydb. (H)

Agrimonia parviflora Aiton $(\mathrm{H})$

Alchemilla pectinata Kunth $(\mathrm{H})$

Alchemilla sibbaldiifolia Kunth $(\mathrm{H})$

Crataegus mexicana Moc. et Sessé (Ab)

Prunus serotina Ehrb. ssp. capuli (Cav.) McVaugh (Am)

Prunus tetradenia Koehne (Am)

Rubus humistratus Steud. (Be)

Rubus spp. (Ar)

\section{RUBIACEAE}

Borreria laevis (Lam.) Griseb. $(\mathrm{H})$

Bouvardia laevis M.Martens et Galeotti (Ar)

Bouvardia ternifolia (Cav.) Schltdl. $(\mathrm{H})$

Bouvardia xylosteoides Hook. et Arn. (H)

Coccocypselum cordifolium Nees et Mart. $(\mathrm{H})$

Crusea longiflora (Willd. ex Roem. et Schult.)

W.R.Anderson $(\mathrm{H})$

Deppea obtusiflora (Benth.) Benth. (Ar) 
Galium mexicanum Kunth $(\mathrm{H})$

Galium orizabense Hemsl. $(\mathrm{H})$

Galium uncinulatum DC. $(\mathrm{H})$

Hoffmannia montana L.O.Williams (Ar)

Mitchella repens $\mathrm{L}$. $(\mathrm{H})$

Palicourea padifolia (Willd. ex Roem et Schult.)

C.M.Taylor et Lorence (Ar)

Randia laetivirens Standl. (Ar)

Randia xalapensis M.Martens et Galeotti (Ar)

Rondeletia capitellata Hemsl. (AAr)

\section{RUTACEAE}

Peltostigma pteleoides (Hook.) Walp. (Ar)

Zanthoxylum clava-herculis $\mathrm{L}$. (Ab)

Zanthoxylum foliolosum F.Donn.Sm. (Be)

Zanthoxylum xicense Miranda (Ab)

SABIACEAE

Meliosma alba (Schltdl.) Walp. (Am)

SAPINDACEAE

Serjania sp. (Be)

\section{SAXIFRAGACEAE}

Heuchera orizabensis Hemsl. (H)

Philadelphus mexicanus Schltdl. (Be)

\section{SCROPHULARIACEAE}

Castilleja arvensis Schltdl. et Cham. (H)

\section{SIMAROUBACEAE}

Picramnia xalapensis Planch. (Ar)

\section{SOLANACEAE}

Athenaea viscosa (Schrad.) Fernald $(\mathrm{H})$

Cestrum elegans (Brongn.) Schltdl. (Ar)

Cyphomandra betacea (Cav.) Sendtn. (Ar)

Datura sp. (Ar)

Jaltomata procumbens (Cav.) J.L.Gentry $(\mathrm{H})$

Physalis cordata Mill. (H)

Solandra guttata D.Don (Be)

Solanum acerifolium Dunal (Ar)

Solanum aligerum Schltdl. (AAr)

Solanum aphyodendron S.Knapp (Ar)

Solanum appendiculatum Dunal (Be)

Solanum chrysotrichum Schltdl. (Ar)

Solanum diflorum Vell. (Ar)

Solanum erianthum D. Don (Ab)

Solanum nigricans M.Martens et Galeotti (Ar)

Solanum schlechtendalianum Walp. (Ar)
Solanum skutchii Correll (Be)

Solanum umbellatum Mill. (AAr)

STAPHYLEACEAE

Turpinia occidentalis (Sw.) G.Don (Ab)

STYRACACEAE

Styrax glabrescens Benth. var: pilosus (Perkins) Standl. (Am)

\section{THEACEAE}

Gordonia grandis André (Ar)

Cleyera theaeoides (Sw.) Choisy (Ab)

Ternstroemia huasteca B.M.Barthol. (Ab)

TILIACEAE

Tilia houghi Rose (Am)

Triumfetta acrantha Hochr. (Ar)

Triumfetta grandiflora Vahl (Ar)

\section{ULMACEAE}

Lozanella enantiophylla (Donn.Sm.) Killip et C.V.Morton (AAr)

Trema micrantha (L.) Blume (Ab)

UMBELLIFERAE

Sanicula liberta Cham. et Schltdl. (H)

Prionosciadium sp. $(\mathrm{H})$

\section{URTICACEAE}

Pilea pubescens Liebm. $(\mathrm{H})$

Urera caracasana (Jacq.) Griseb. (Ar)

Urtica mexicana Liebm. (H)

VALERIANACEAE

Valeriana scandens Loefl. (Be)

\section{VERBENACEAE}

Citharexylum hidalgense Moldenke (Ar)

Lantana achyranthifolia Desf. (Ar)

Lantana hirta Graham (Ar)

Lantana velutina M.Martens et Galeotti (Ar)

Verbena elegans Kunth $(\mathrm{H})$

Verbena litoralis Kunth $(\mathrm{H})$

\section{VITACEAE}

Parthenocissus quinquefolia (L.) Planch. (Be)

Vitis bourgaeana Planch. (Be)

Vitis popenoei J.H.Fennell (Be)

Vitis tiliifolia Humb. et Bonpl. ex Roem. et Schult. (Be) 